\title{
Changes in correlation between promoter methylation and gene expression in cancer

\author{
Matahi Moarii ${ }^{1,2,3}$, Valentina Boeva ${ }^{1,2,3}$, Jean-Philippe Vert ${ }^{1,2,3}$ and Fabien Reyal ${ }^{4,5,6^{*}}$
}

\begin{abstract}
Background: Methylation of high-density CpG regions known as CpG Islands (CGIs) has been widely described as a mechanism associated with gene expression regulation. Aberrant promoter methylation is considered a hallmark of cancer involved in silencing of tumor suppressor genes and activation of oncogenes. However, recent studies have also challenged the simple model of gene expression control by promoter methylation in cancer, and the precise mechanism of and role played by changes in DNA methylation in carcinogenesis remains elusive.

Results: Using a large dataset of 672 matched cancerous and healthy methylomes, gene expression, and copy number profiles accross 3 types of tissues from The Cancer Genome Atlas (TCGA), we perform a detailed meta-analysis to clarify the interplay between promoter methylation and gene expression in normal and cancer samples. On the one hand, we recover the existence of a CpG island methylator phenotype (CIMP) with prognostic value in a subset of breast, colon and lung cancer samples, where a common subset of promoter CGIs hypomethylated in normal samples become hypermethylated. However, this hypermethylation is not accompanied by a decrease in expression of the corresponding genes, which are already lowly expressed in the normal genes. On the other hand, we identify tissue-specific sets of genes, different between normal and cancer samples, whose inter-individual variation in expression is significantly correlated with the variation in methylation of the $3^{\prime}$ flanking regions of the promoter CGls. These subsets of genes are not the same in the different tissues, nor between normal and cancerous samples, but transcription factors are over-represented in all subsets.
\end{abstract}

Conclusion: Our results suggest that epigenetic reprogramming in cancer does not contribute to cancer development via direct inhibition of gene expression through promoter hypermethylation. It may instead modify how the expression of a few specific genes, particularly transcription factors, are associated with DNA methylation variations in a tissue-dependent manner.

Keywords: Epigenetic regulation, Cancer, CpG Island methylator phenotype

\section{Background}

DNA methylation is one of the main epigenetic mechanisms, alongside histone modifications, that plays a significant role in gene silencing [1], tissue differentiation [2], cellular development [3], X-chromosome inactivation [4], or genetic imprinting [5]. Aberrant hyper-methylation of high-density $\mathrm{CpG}$ regions known as CpG Islands (CGIs) [6] and genome-wide hypo-methylation [7] have

\footnotetext{
${ }^{*}$ Correspondence: fabien.reyal@curie.fr

${ }^{4}$ UMR932, Immunity and Cancer Team, Institut Curie, 26 Rue d'UIm, 75006

Paris, France

${ }^{5}$ Department of Translational Research, Residual Tumor and Response to

Treatment Team, Institut Curie, 26 Rue d'Ulm, 75006 Paris, France

Full list of author information is available at the end of the article
}

often been associated with cancer and there has been an increasing effort to understand the specific epigenetic modifications that contribute to carcinogenesis [8-10]. In addition to promoter CGIs themselves, their surrounding area called shores (up to $2 \mathrm{~kb}$ from CGIs) and shores ( $2 \mathrm{~kb}$ to $4 \mathrm{~kb}$ from CGIs) have also a cancer- and tissue-specific methylation [11], while even larger cancer-specific methylation variations were reported in so called open sea regions, far from CGIs [12]. In this study, we focus on methylation in promoter CGIs and surrounding regions only, in order to investigate its association in cis with gene expression. 
The possibility to quantify DNA methylation genomewide on normal and cancer tissues, with microarray or sequencing technologies, has triggered a lot of data-driven research to clarify the role of methylation in gene regulation and cancer. Several studies have highlighted a correlation between differentially methylated regions near promoter regions and gene expression changes [13-17]. However, it has also been reported that aberrant overmethylation occurs mostly in normally down-regulated genes, questioning the role of methylation as a causal mechanism for gene repression [18-21]. More recently, Timp et al. have proposed a model where epigenetic aberrations contribute to carcinogenesis by dysregulating the functions of specific genes that regulate the epigenome itself [22, 23]. Reddington et al. speculate that epigenetic reprogramming might lead to an altered Polycomb binding landscape which could impact genome regulation [24].

To gain further insight into the role of DNA methylation in cancer, we perform a large-scale meta-analysis of methylation profiles of normal and cancerous samples from multiple tissues from The Cancer Genome Atlas (TCGA). For each CGI and surrounding area, we focus on (i) its average methylation profile and (ii) the association between variations of its methylation profile and variations in the expression of the target gene. Comparing these parameters between normal and cancerous samples of different tissues suggests that the interplay between promoter methylation and gene expression, and how they are modified in cancer, is not simple. On the one hand, while each promoter CGI tends to be either hypo- or hypermethylated in all normal samples, we observe hypermethylation of a common subset of CGIs in several cancer samples of different tissues (breast, lung and colon), supporting the existence of a CpG island methylator phenotype (CIMP) with prognostic value, as introduced by Toyota et al. [25]. However, we did not find evidence that the genes associated with hypermethylated promoter CGIs were less expressed in the cancer samples, as most of the genes concerned are already lowly expressed in normal tissues, as already observed by [19]. On the other hand, looking more precisely at associations between promoter methylation level and gene expression within a set of samples, we observe for each tissue and each normal or cancerous sample set a subset of genes, different from the genes hypermethylated in the CIMP phenotype, for which this association is important and strongest outside of the CGIs, namely in the N-shores and N-shelves. This subset of genes varies across tissues but also whether we consider healthy or cancerous samples. However, transcription factors are over-represented in all subsets. This suggests that epigenetic reprogramming might contribute to carcinogenesis in part by modifying gene expression susceptibility to changes in DNA methylation.

\section{Results}

Classification of genes based on their CGI methylation profiles in normal and cancerous tissues

We first assess how promoter methylation profiles differ between genes, when for each gene we consider the average methylation profile across normal or cancerous samples. For that purpose, we collected highdensity methylation datasets from the cancer genome atlas (TCGA) data portal providing more than $485 \mathrm{~K} \mathrm{CpG}$ methylation levels for 672 normal and cancerous samples from three tissues of origin: breast, colon and lung (Table 1). For each CGI, we combine the probes in the CGI and in the shore and shelves of the CGI, defined as the regions up to $4 \mathrm{~kb}$ outside of the CGI [11], in a unique CGI, shores and shelves (CGI+SS) methylation profile. We restrict our analysis to the $1827 \mathrm{CGI}+\mathrm{SS}$ where at least 20 CpG probes are measured by the technology in order to have high enough coverage to measure the methylation variation within each CGI+SS. For each of the three tissue of origin, and each normal or cancerous set of tissues, we compute the average methylation profile of each CGI+SS by averaging the methylation values of each $\mathrm{CpG}$ across the samples. Hence we compute $3 \times 2=6$ average profile for each CGI+SS, with we refer to below as CGI+SS signatures.

To assess the diversity of CGI+SS signatures across genes, we perform an unsupervised classification of all signatures for each of the 6 types of samples, using Ward hierarchical clustering. Since different CGI+SS may contain a different number of GpG probes, we use a specific distance based on dynamic time warping to compare signatures of different lengths. Figure 1a shows the CGI+SS clustering obtained for signatures measured on normal samples from breast samples. Similar figures were obtained for lung (Additional file 1a) and colon samples (Additional file 2a). We observe two clusters, which are largely conserved across the 3 tissues of origin (Table 2). To clarify the types of signatures captured by each cluster, we represent on a standardized CGI+SS $x$-axis the 10

Table 1 Patients dataset. Original dataset sizes for methylation (Meth), gene expression (GE) and CNV profiles for normal (N) or cancerous (C) tissues. The "Matched" column represents the final dataset containing samples with matched methylation, gene expression and copy number profiles

\begin{tabular}{lllllllll}
\hline & \multicolumn{3}{c}{ Meth } & \multicolumn{2}{c}{ GE } & \multicolumn{2}{c}{ CNV } & \multicolumn{2}{c}{ Matched } \\
\hline & N & C & N & C & N & C & N & C \\
Breast & 97 & 626 & 100 & 778 & 1073 & 1041 & 70 & 474 \\
Colon & 38 & 291 & 0 & 193 & 0 & 470 & 0 & 33 \\
Lung & 32 & 452 & 37 & 125 & 568 & 516 & 13 & 82 \\
Total & 167 & 1370 & 137 & 1096 & 1641 & 1981 & 83 & 589 \\
\hline
\end{tabular}




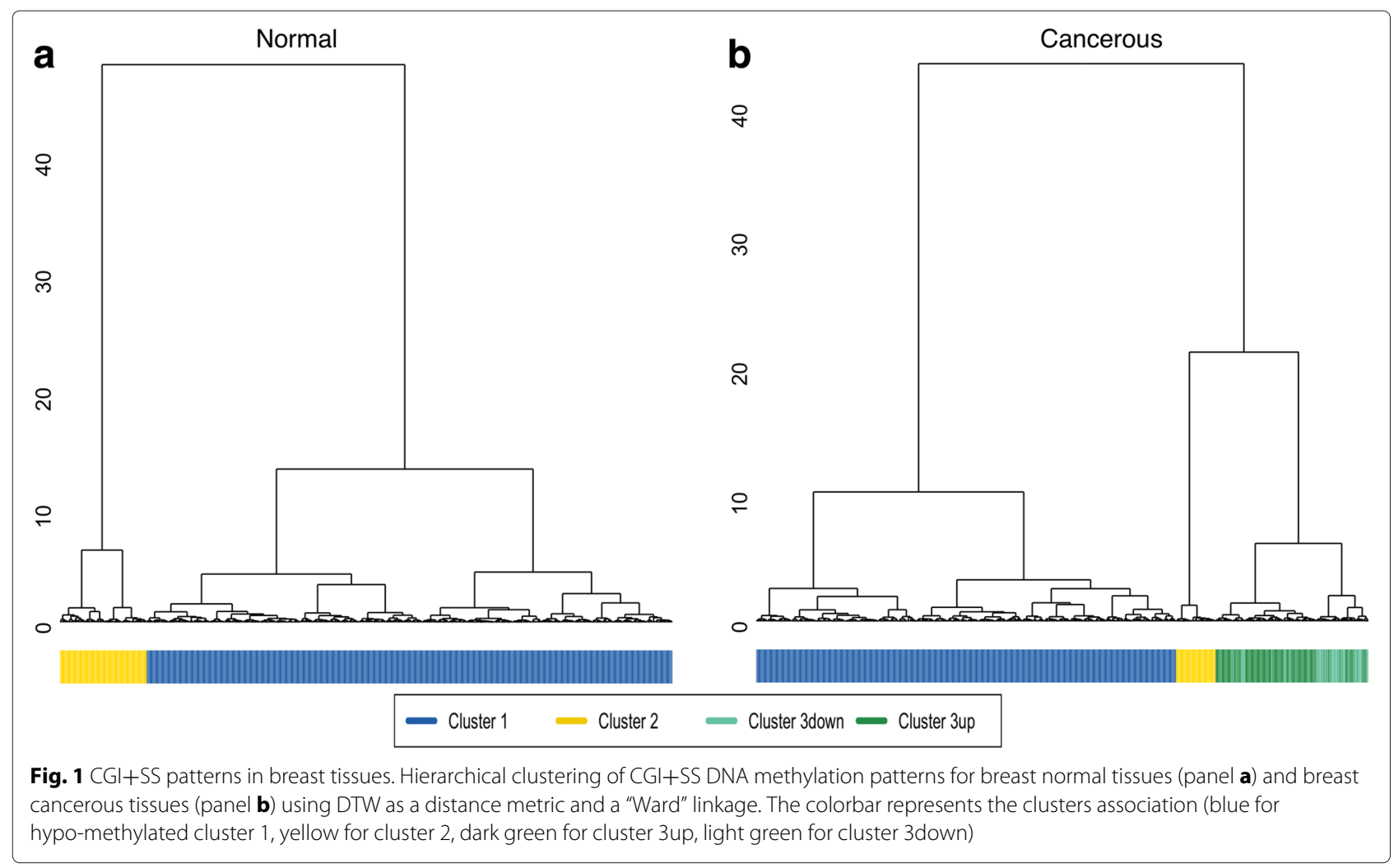

medoid CGI+SS signatures for each cluster and each tissue (Fig. 2a, Additional files 3a and 4a). We clearly observe that the large cluster 1 , which contains about $90 \%$ of all $\mathrm{CGI}+\mathrm{SS}$, corresponds to hypo-methylated islands with hemi-methylated CGI shores and hyper-methylated CGI shelves, while the smaller cluster 2 contains about $10 \%$ of CGI+SS which are fully hyper-methylated. A closer look at cluster 1 shows that, in some cases, the variation of methylation between islands and shores is unclear, in

Table 2 Concordance analysis of CGI+SS patterns clusters between normal tissues

\begin{tabular}{llll}
\hline Clusters & \multicolumn{3}{c}{ Colon } \\
\hline Breast & 1 & & 2 \\
1 & 1560 & & 9 \\
2 & 113 & & 145 \\
Clusters & & Lung & \\
Colon & 1 & & 2 \\
1 & 1610 & & 7 \\
2 & 63 & & 147 \\
Clusters & & Breast & \\
Lung & 1 & & 2 \\
1 & 1549 & & 20 \\
2 & 68 & & 190 \\
\hline
\end{tabular}

the sense that some shores are fully hypo-methylated. As CGIs, shores and shelves regions are delimited based on somehow arbitrary criteria, a systematic analysis of these signatures could lead to a refinement of currently accepted boundaries.

Performing the same unsupervised classification independently on signatures obtained from the three types of cancerous tissues leads to different results, with the apparition of a third stable cluster (Fig. 1b for breast, Additional files $1 \mathrm{~b}$ and $2 \mathrm{~b}$ for lung and colon, respectively). Comparing the clusters of normal and cancerous tissues shows that, for all types of tissues, the first two clusters found in cancerous tissues are mostly composed of CGI+SS of the corresponding clusters in normal tissues, while the CGI+SS in the third cluster, specifically found in cancerous tissues, tend to come evenly from both clusters in normal tissues (Table 3). A look at representative signatures of each cluster (Fig. $2 \mathrm{~b}$ for breast, Additional files $3 \mathrm{~b}$ and $4 \mathrm{~b}$ for lung and colon, respectively) confirms that clusters 1 and 2 contain respectively hypo- and hyper-methylated profiles, just like the respective clusters in normal tissues, while cluster 3 contains CGI+SS signatures which are hemi-methylated (Additional file 5). Separating the CGI+SS in cluster 3 into sub-clusters "3up" and "3down", depending on whether they are in cluster 1 or 2 in normal tissues, we further see that the level of methylation of CGI+SS signatures in 


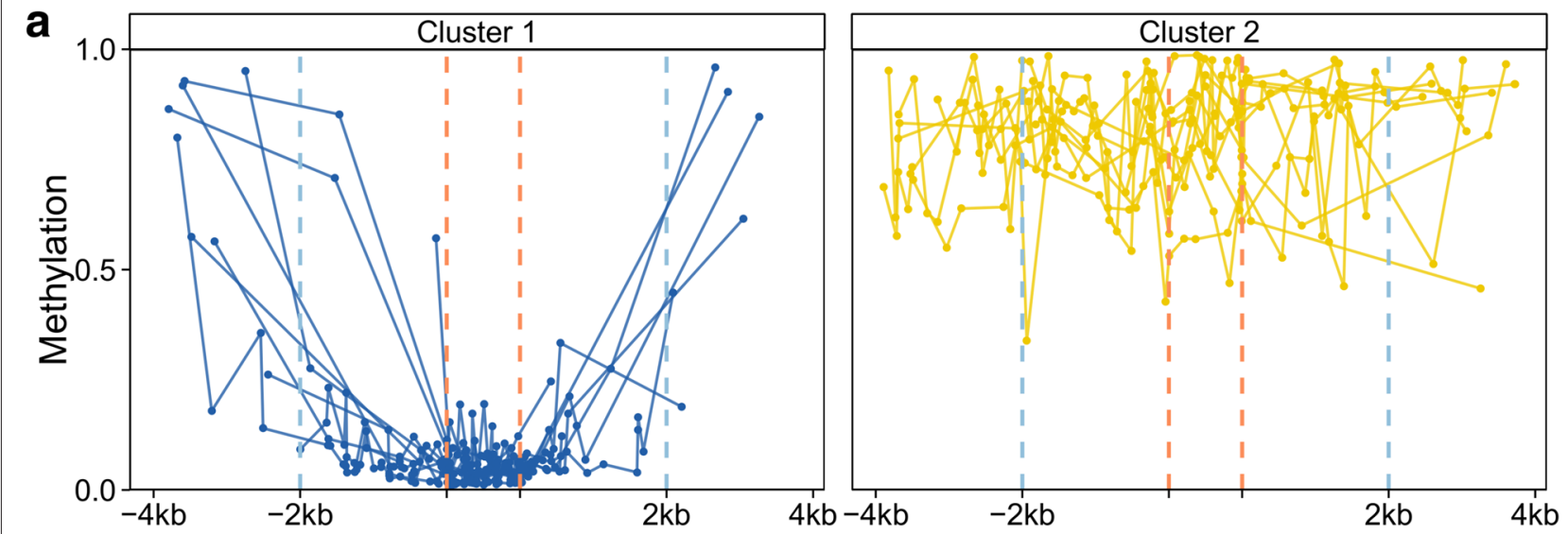

b
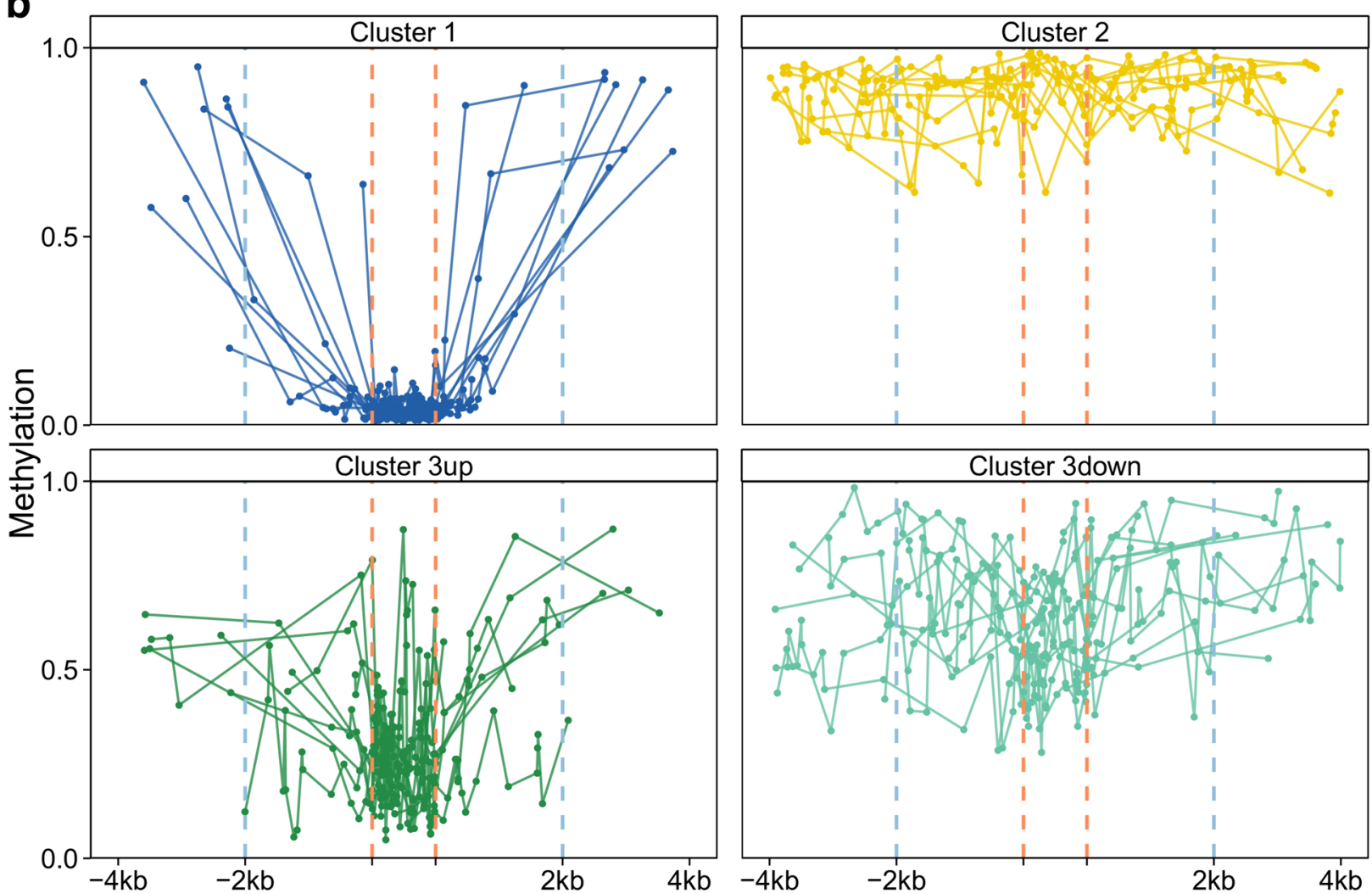

Fig. 2 Characteristic profiles for each clusters. Visualization of the CGI+SS DNA methylation signatures as condensed profiles from the 10 medoids profiles for each clusters in breast normal (panel a) or cancerous (panel b) tissues. The two orange dashed lines represent the normalized $1 \mathrm{~kb}$ long CGI region while the two blue lines represent the $2 \mathrm{~kb}$ limit between shores and shelves regions

the "3up" sub-cluster tends to be lower than the level of methylation of CGI+SS signatures in the "3down" subcluster (5 to 8 fold decrease). Interestingly, cluster 3 is mostly conserved between tissues (Fig. 3), suggesting that these epigenetic variations might be associated with a tissue-independent carcinogenesis process.
In summary, this global analysis of methylation signatures suggests the existence of four types of CGI+SS largely conserved across tissues: the majority of them remains hypo-methylated on the CGI and hypermethylated on the shores and shelves in normal and cancerous tissues (cluster 1); a minority is hyper-methylated 
Table 3 Concordance analysis of CGI+SS patterns clusters from normal to cancerous tissues. Each table represents the concordance of clusters between normal and cancerous clustering analysis

\begin{tabular}{lll}
\hline Breast & \multicolumn{3}{c}{ Normal } \\
\hline Cancerous & 1 & 2 \\
1 & 1231 & 21 \\
2 & 9 & 109 \\
3 & 329 & 128 \\
Lung & & Normal \\
Cancerous & 1 & 2 \\
1 & 1128 & 12 \\
2 & 18 & 168 \\
3 & 471 & 30 \\
Colon & & Normal \\
Cancerous & 1 & 2 \\
1 & 1112 & 11 \\
2 & 13 & 106 \\
3 & 548 & 37 \\
\hline
\end{tabular}

in normal and cancerous tissues (cluster 2); finally, a fraction of CGI+SS signatures is hypo-methylated in normal tissues and partly methylated in cancerous tissues (cluster 3up), while another fraction is hyper-methylated in normal tissues and partly methylated in cancerous ones (cluster 3down). To clarify whether these four categories

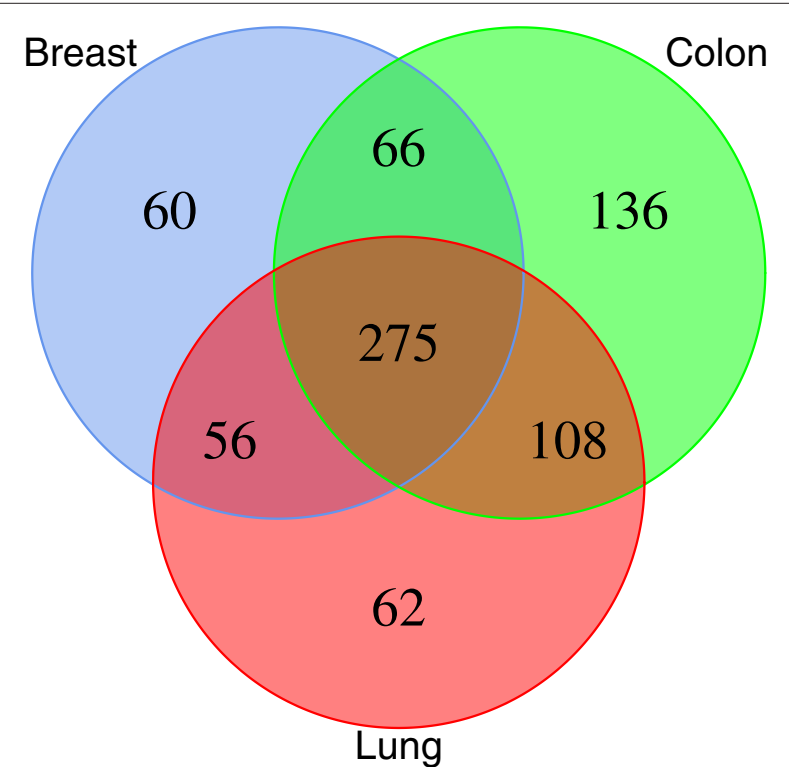

Fig. 3 Stability of the cancerous-specific cluster between tissues. Venn diagram representing the intersection of the CGI+SS associated with cancerous-specific cluster 3 for each tissue or CGI+SS are associated to particular biological functions, we performed a gene functional enrichment analysis [26] of the genes associated to the CGI+SS in each of the four categories, for each tissue. Results are shown in Additional file 6. Restricting ourselves to Gene Ontology (GO) biological processes associated to at least 20 genes, we found that the large cluster 1 is mostly enriched in genes involved in metabolic processes, while the cancerspecific cluster 3up is enriched in genes involved in developmental processes. There was no significant functional enrichment for genes in cluster 2 and 3down.

\section{Cancer-specific methylation does not repress gene expression but instead targets genes lowly expressed in normal tissues}

CGI methylation is often associated with gene expression silencing. We therefore assess whether the CGI+SS clusters defined above, corresponding roughly to lowly methylated (clusters 1 ), highly methylated (cluster 2 ) or partially methylated in cancer (cluster 3) CGI+SS, are associated with different mean levels of gene expression. In normal breast tissues, we indeed observe that genes near hypomethylated islands in cluster 1 are slightly but significantly less expressed than genes near an hyper-methylated islands in cluster 2 (Fig. $4 \mathrm{a}, P_{\text {Breast }}=0.02$ ). There is however no significant difference between the two clusters in normal lung tissues (Additional file $7 \mathrm{a}, P_{\text {Lung }}=0.39$ ), and we could not test the hypothesis on normal colon tissues since we have none with both methylation and expression data (Table 1). In cancerous samples, we observe that genes near a CGI+SS in the cancer-specific cluster 3 have a significantly lower expression than other genes (Fig. $4 \mathrm{~b}$, Additional files $7 \mathrm{~b}$ and $\left.8, P_{\text {Breast }}, P_{\text {Lung }}, P_{\text {Colon }}<10^{-16}\right)$, particularly for the genes near a CGI+SS in the "3up" cluster. As genes in the "3up" cluster are hypo-methylated in normal tissues, this could suggest that their cancerspecific methylation is a way to repress their expression in cancer. However, a closer look at the expression of these genes in normal tissues (Fig. 4c, Additional file 7c) shows that they are already lowly expressed in normal tissues. This suggests that instead of activating CGI methylation to silence to genes, cancer cells instead activates CGI methylation of hypo-methylated genes which are already lowly expressed in normal tissues.

\section{Cancer-specific methylation is an independent predictor of patient survival in breast cancer}

Our analysis so far compares CGI+SS in terms of their mean methylation across a set of samples and does not take into account between-sample variations. CGI+SS associated with cluster 1 (resp. 3) are hypo- (resp. hyper-) methylated on average, which indicates that there is little to no variations between samples. However, signatures of CGIs in the cancer-specific cluster 3 are partly 

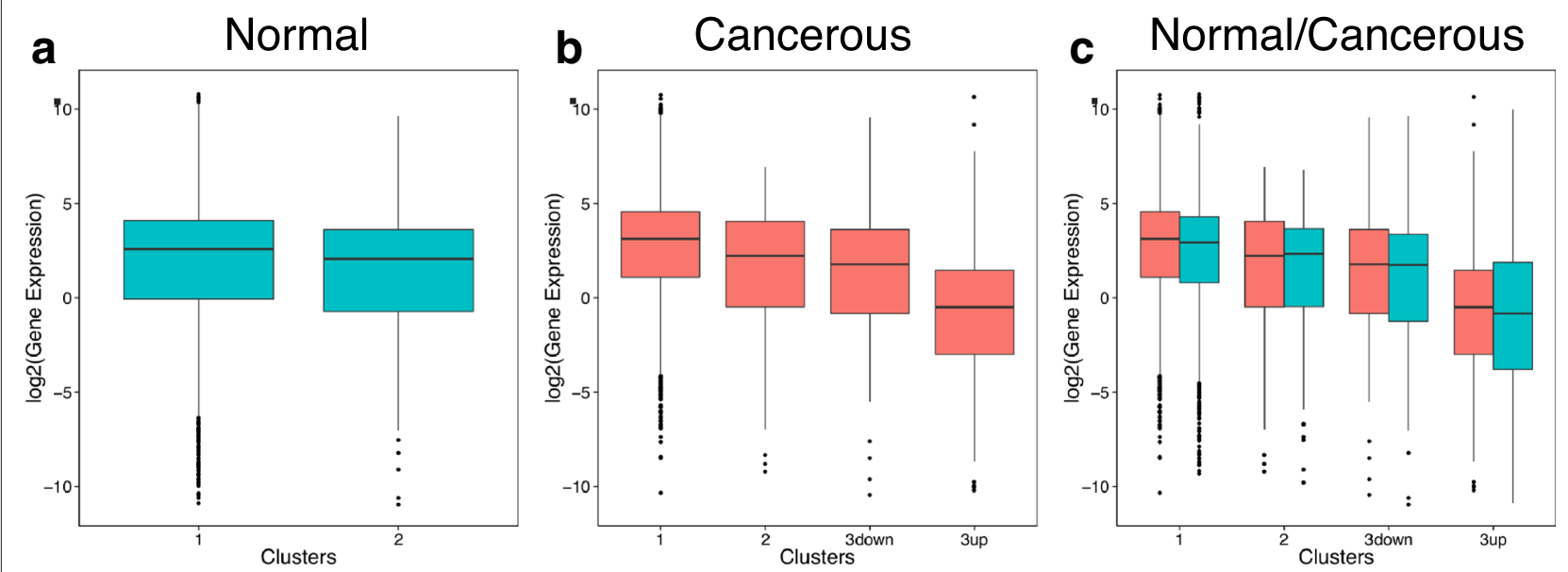

Fig. 4 Distribution of gene expression in different clusters for in breast tissues. Gene expression distribution for genes based on the cluster assignment of their associated CGI+SS. Panel a Gene expression distribution in normal breast tissues shows a slight repression for genes associated with cluster 2 (hyper-methylated CGI+SS profiles). "Ref" represents the genome-wide gene expression distribution Panel b Gene expression profiles in cancerous breast tissues shows high repression for genes associated with cluster 3 and specifically cluster "3up" (hemi-methylated CGI+SS profiles). Panel c Gene expression profiles in both normal and cancerous breast tissues using the cluster assignement in cancerous tissues shows that genes associated with cluster "3up" in cancerous tissues define a cluster of genes already repressed in normal tissues

methylated, which can either hide the fact that they are hemi-methylated for most cancerous samples, or that they are highly variable between samples. We therefore assess whether the partial methylation of CGI+SS signatures in cluster 3 is related to an overall increase (for cluster 3up) or decrease (for cluster 3down) in methylation for all or most of the patients, or if this it is caused by a subset of patients that become hyper- (resp. hypo-)methylated for these CGI+SS.

For that purpose, we first summarize the methylation of each CGI+SS on each breast cancer sample by a single value, the average methylation of the probes in the CGI+SS. We then represent each sample by the vector of methylation values of the CGI+SS in cluster 3up, and perform a Ward hierarchical clustering of the cancerous samples based on this representation. The resulting clustering is shown in Fig. 5a, where in addition we indicate the ER+, HER2 and survival information for each patient. We observe that the distribution methylation values is very bimodal, and that the hyper-methylation of a given CGI+SS from cluster 3up generally happens in a subset of patients only. Interestingly, we see that the same subset of patients tends to be simultaneously hyper-methylated for all CGI+SS from cluster 3up, suggesting that hypermethylation of these islands is a characteristics of a subset of the tumors. This allows us to divide the set of breast cancer patients in three clusters given the level of methylation in cluster 3up as either "low", "intermediate", or "high" (Fig. 5a). Interestingly, distinguishing patients given the level of methylation from the CGI+SS in cluster 3up is significantly predictive of the patient survival (Fig. 5b, logrank, $p=0.01$ ). Surprisingly, the cluster with the lowest survival is the "intermediate" cluster encompassing a portion but not all of the triple negative breast cancers $(65 \%$ in cluster 3up "low", $32 \%$ in cluster 3up "intermediate" and only $3 \%$ in cluster 3up "high"). A multivariate Cox proportional hazards regression model fitted with available clinical parameters (tumor size, lymph node status, hormone receptor status, HER2/NEU status and patient's age) further shows that this stratification of patients based on the methylation level of genes in cluster 3up adds prognostic value independently of other clinical features (Table 4, Additional file 9). These results support the existence of a CpG island methylator phenotype (CIMP) as introduced by Toyota et al. [25] that is clinically relevant to assess the survival of patients. More importantly, they suggest that low survival might not be associated with a positive or negative CIMP, but with an intermediate phenotype termed as CIMP-low [27].

A similar analysis on CGI+SS associated with cluster 3down is less conclusive, and does not clearly cluster patients in separate clusters (Additional file 10). A lack of sufficient survival data for colon and lung tissues prevented a similar analysis for these tissues.

\section{Methylation of $\mathrm{CpG}$ in the $3^{\prime}$ region outside the CGI is the most correlated with gene expression}

Our analysis so far compares CGI+SS to one another, by looking at their average methylation profiles across collections of samples. We found no clear evidence for a correlation between mean methylation level of a CGI and mean expression level of the corresponding genes, but this may be due to the fact that many other factors impact the expression level of a gene, including biological 


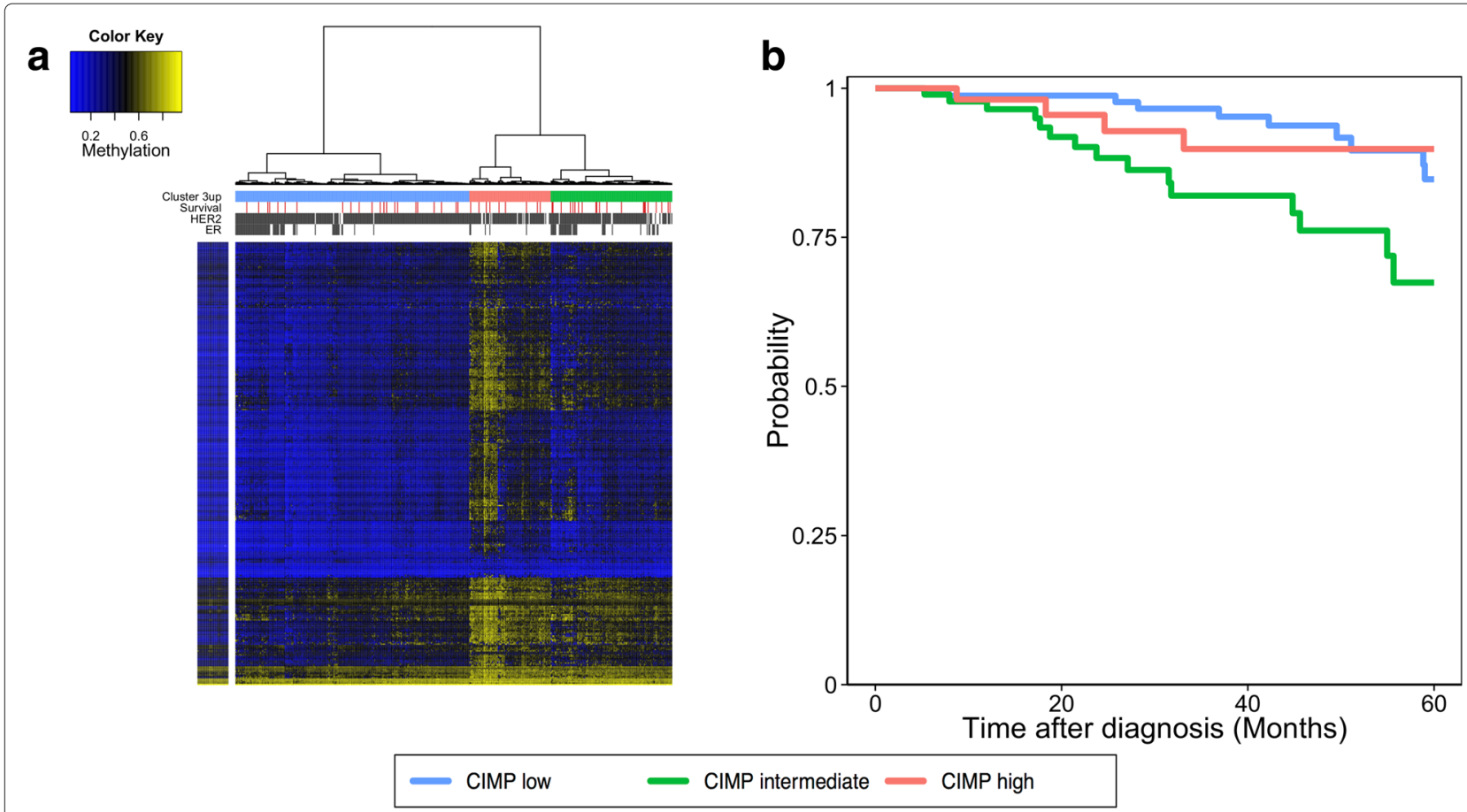

Fig. 5 Cluster 3 up methylation is a predictive factor for survival of patients in breast cancer patients. Panel a Hierarchical clustering of breast cancer patients given the average methylation level of all the CGI+SS associated with cluster 3up. The row color bar represents the average methylation level for the same CGI+SS in healthy breast tissues. The column color bar gives clinical information about the patients such as ER and HER2 statuses (grey for negative and white for positive), survival information (white for positive overall survival within 5 years and red for death within 5 years). The top row of the column color bar represents the three classes distinguished by methylation profiles in cluster 3up (blue for cluster 3up "low", green for cluster 3up "intermediate" and pink for cluster 3up "high"). Panel b Kaplan-Meier estimate of breast cancer patient survival given the cluster 3 up class (blue for cluster 3up "low", green for cluster 3up "intermediate" and pink for cluster 3up "high") shows that cluster 3up "intermediate" patients have a significantly higher risk of death within 5 years than either cluster 3 up "low" or "high" patients (Log-rank, $p=0.01$ )

and technical ones. Another way to assess how methylation impacts expression is to look, for each given gene, how variation in expression across samples correlates with variations in methylation of nearby CGIs. For each set of samples (split by tissue of origin and normal/cancerous state), we measure the strength of association between methylation and expression for each gene by computing a predictive goodness of fit $R^{2}$ which represents the level of gene expression variation explained by CGI+SS methylation variation (see Materials and methods). This

Table 4 Multivariate Cox regression analysis including the level of methylation in the cancer-specific cluster "3up" in addition to significant clinical variables for breast cancer

\begin{tabular}{lll}
\hline Clinical variable (Reference) & HR $(95 \% \mathrm{Cl})$ & $p$-value \\
\hline Cluster 3up (Low vs intermediate) & $3.44(1.44-8.23)$ & 0.007 \\
Cluster 3up (Low vs high) & $1.92(0.50-7.34)$ & 0.34 \\
(ER,HER2) (-/-vs +/-) & $0.37(0.15-0.88)$ & 0.026 \\
(ER,HER2) (-/-vs -/+) & $1 \times 10^{-8}(0-$ Inf $)$ & 1 \\
(ER,HER2) (-/-vs +/+) & $0.53(0.09-2.94)$ & 0.46 \\
Lymph Node (Negative) & $4.51(1.63-12.44)$ & 0.004 \\
\hline
\end{tabular}

coefficient is calculated either when the CGI+SS methylation status is summarized by the mean methylation values of all the probes, or by using the full CGI+SS methylation information of each probe.

We observe that the full CGI+SS methylation profile is predictive of gene expression for a subset of genes in each dataset, and that this predictive power is significantly higher than using only the average CGI+SS methylation (Fig. 6, Additional files 11a, b, $P_{\text {Breast }}<10^{-16}, P_{\text {Lung }}=$ $\left.1.3 \times 10^{-16}, P_{\text {Colon }}=3.2 \times 10^{-5}\right)$. We provide in Table 5 the list of the top 50 genes based on their predictive score in cancerous breast tissues and similar lists for normal breast, lung and colon tissues in Additional file 12. Among the 2,374 genes studied, 139 genes are associated with more than one CGI+SS. For these genes, the predictive power is computed using the CGI+SS closest to the TSS. Using all the CGI+SS for these genes do not yield significant improvement over taking only the CGI+SS closest to the TSS except for breast tissues $\left(P_{\text {Breast }}=0.003\right.$, $P_{\text {Lung }}=0.15, P_{\text {Colon }}=0.62$ ). We also observe no association between the predictive goodness of fit $R^{2}$ and the CGI + SS clusters described above $\left(P_{\text {Breast }}=0.48, P_{\text {Lung }}=\right.$ $\left.0.47, P_{\text {Colon }}=0.44\right)$. 


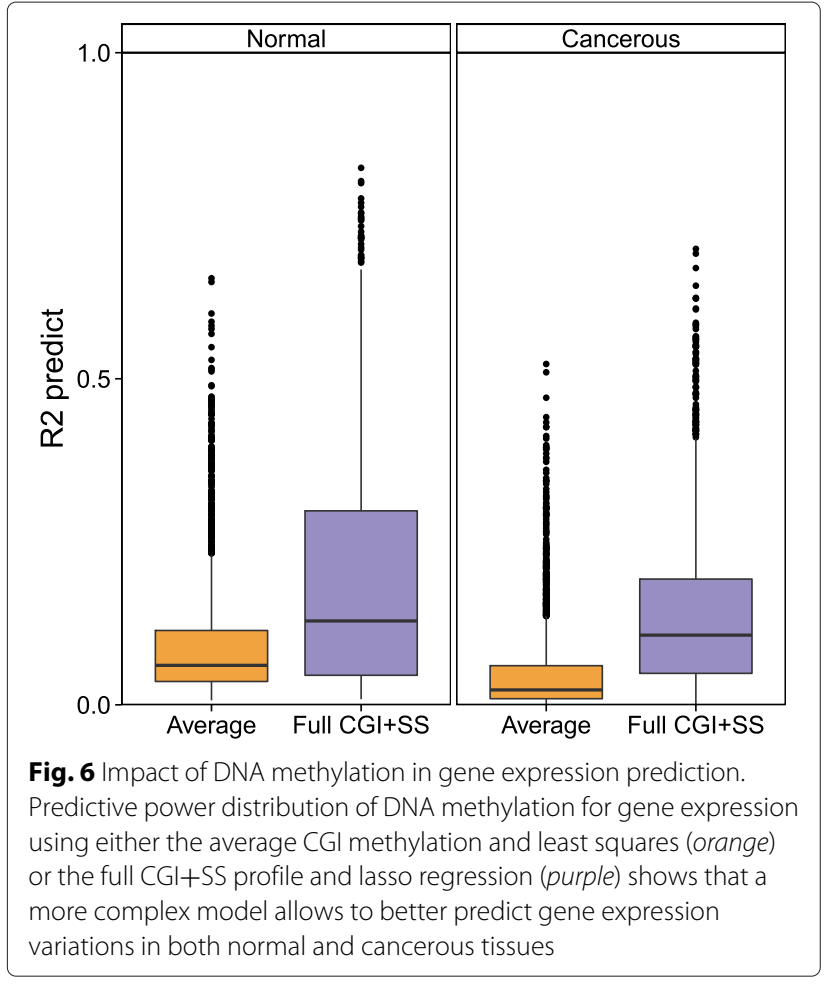

Since the predictive power of multivariate models based on all CpG probes in a CGI+SS is larger than the predictive power of the mean methylation value only, we now investigate which $\mathrm{CpG}$ in a CGI+SS are particularly important predictors of expression. For that purpose, we measure the correlation between the methylation of individual CpG and gene expression for the 50 genes with the largest predictive $R^{2}$, and summarize the correlation values based on the position of the probe in the CGI+SS in Fig. 7 for breast samples (Additional file 13 for colon and lung). As expected, we observe overall a negative correlation between methylation and gene expression, and notice that this association is stronger in CGI shores and shelves located in the 3' region than in the CGI itself. This is coherent with results in [11] stating that variations in the CGI are less critical than variations in proximity regions of the CGI. Performing the same analysis by varying the number of genes selected to compute correlations from 20 to 100 gave similar results.

\section{Correlation between gene expression and promoter methylation is tissue-specific, and is modified in cancer tissues but overall targets transcription factors}

Results in the previous section suggest that for a subset of genes, a significant correlation between promoter methylation and gene expression is observed, which may be due for example to a direct regulation of gene expression by promoter methylation. To assess whether this correlation
Table 5 Genes regulated by methylation in breast cancer

\begin{tabular}{|c|c|}
\hline Gene & Score \\
\hline$D Q \times 1$ & 0.6993144 \\
\hline IRS2 & 0.6920052 \\
\hline GPSM3 & 0.6698851 \\
\hline FOXCl ${ }^{\dagger}$ & 0.6428115 \\
\hline PSMB9 & 0.6242704 \\
\hline $\mathrm{HOXC10^{ \dagger }}$ & 0.6233063 \\
\hline NDRG2 & 0.6230449 \\
\hline MAPT & 0.6078226 \\
\hline STC2 & 0.6064161 \\
\hline ZNF502 & 0.5859661 \\
\hline PTPRCAP & 0.5834326 \\
\hline SCAND3 & 0.5832075 \\
\hline SLC1A4 & 0.5801594 \\
\hline TAP1 & 0.5763637 \\
\hline DBNDD2 & 0.5650488 \\
\hline OTX $1^{\dagger}$ & 0.5648463 \\
\hline TCF7 & 0.5618545 \\
\hline LY6G6C & 0.5618097 \\
\hline FERMT3 & 0.5602340 \\
\hline $\mathrm{ZIC4}$ & 0.5595657 \\
\hline$H L A-B$ & 0.5565054 \\
\hline GDF9 & 0.5517472 \\
\hline SOX9† & 0.5513052 \\
\hline CELSR1 & 0.5502329 \\
\hline SYS1-DBNDD2 & 0.5490248 \\
\hline$H L A-E$ & 0.5490118 \\
\hline CYPIBI & 0.5411610 \\
\hline RUNX3 & 0.5406337 \\
\hline KIAA1949 & 0.5379938 \\
\hline RIPK4 & 0.5313998 \\
\hline TPPP2 & 0.5305543 \\
\hline$H L A-F$ & 0.5304392 \\
\hline PPPIR3C & 0.5293955 \\
\hline HOXB5 ${ }^{\dagger}$ & 0.5287862 \\
\hline CELSR3 & 0.5272638 \\
\hline B3GNT5 & 0.5259399 \\
\hline ME3 & 0.5244800 \\
\hline TMC8 & 0.5231671 \\
\hline AlF1 & 0.5223122 \\
\hline SLC39A6 & 0.5217374 \\
\hline $\mathrm{HOXC11^{ \dagger }}$ & 0.5122936 \\
\hline ERBB2 & 0.5055868 \\
\hline TBC1D10C & 0.5038227 \\
\hline SIM2 & 0.5030521 \\
\hline
\end{tabular}


Table 5 Genes regulated by methylation in breast cancer Continued

CAMK2N1

0.5022371

RGMA

LOC100132215

PAXG ${ }^{\dagger}$

VANGL2

DDHD2

0.4996740

0.4979089

0.4976355

0.4960224

0.4879724

Gene: Top scoring genes ranked by the predictive power of methylation to predict gene expression variation. Score: $R^{2}$ score associated. Transcription factors are highlighted with a $\dagger$

is conserved across tissues, we compare the predictive powers of methylation for each gene when it is computed on normal or cancerous samples from different tissues. As shown on Additional file 14, however, we observe little correlation between the predictive power across tissues in normal and in cancer samples, suggesting that the association between promoter methylation and gene expression is tissue-specific $\left(R_{\text {Breast } / \text { Lung }}^{2, \text { Normal }}=0.04, R_{\text {Breast } / \text { Lung }}^{2 \text { Cancerous }}=0.17\right.$, $\left.R_{\text {Lung } / \text { Colon }}^{2 \text {,Cancerous }}=0.07, R_{\text {Colon } / \text { Breast }}^{2 \text {,Cancerous }}=0.06\right)$. We also observe very little correlation between predictive powers in normal and cancerous tissues, which could suggests a shift of the epigenetic regulation mechanism during cancer development (Fig. 8, Additional file 15, $R_{\text {Breast }}^{2}=0.05, R_{\text {Lung }}^{2}=$ $\left.6 \times 10^{-7}\right)$.

Many mechanisms besides DNA methylation are involved in gene expression regulation. In particular, transcription factors (TF) play a critical role in the recruitment of RNA polymerase that allows gene transcription [28]. We noticed that the list of the 50 genes with the largest predictive $R^{2}$ score in each tissue is significantly enriched in TFs as collected from [29], suggesting that methylation may play an important role in the gene regulatory process of transcription factors $\left(P_{\text {Breast }}=0.03, P_{\text {Lung }}=3 \times 10^{-4}\right.$, $\left.P_{\text {Colon }}=0.02\right)$. Using the TF list obtained from [30] yields similar conclusions, as well as varying the number of genes selected from 20 to 100 .

\section{Copy number variations in cancer is an independent factor correlated with gene expression}

In cancer, aberrant DNA copy number variations (CNVs) can have an important impact on gene expression phenotypes [31]. Since genome-wide DNA copy number information is available for all samples analyzed in this study, we now perform an integrated analysis combining methylation, DNA copy number and gene expression. We compute a predictive goodness of fit $R^{2}$ to represents the power of DNA copy number information alone to predict gene expression, on the one hand, and a multidimensional regression model combining both the full CGI+SS DNA methylation information and the DNA copy number

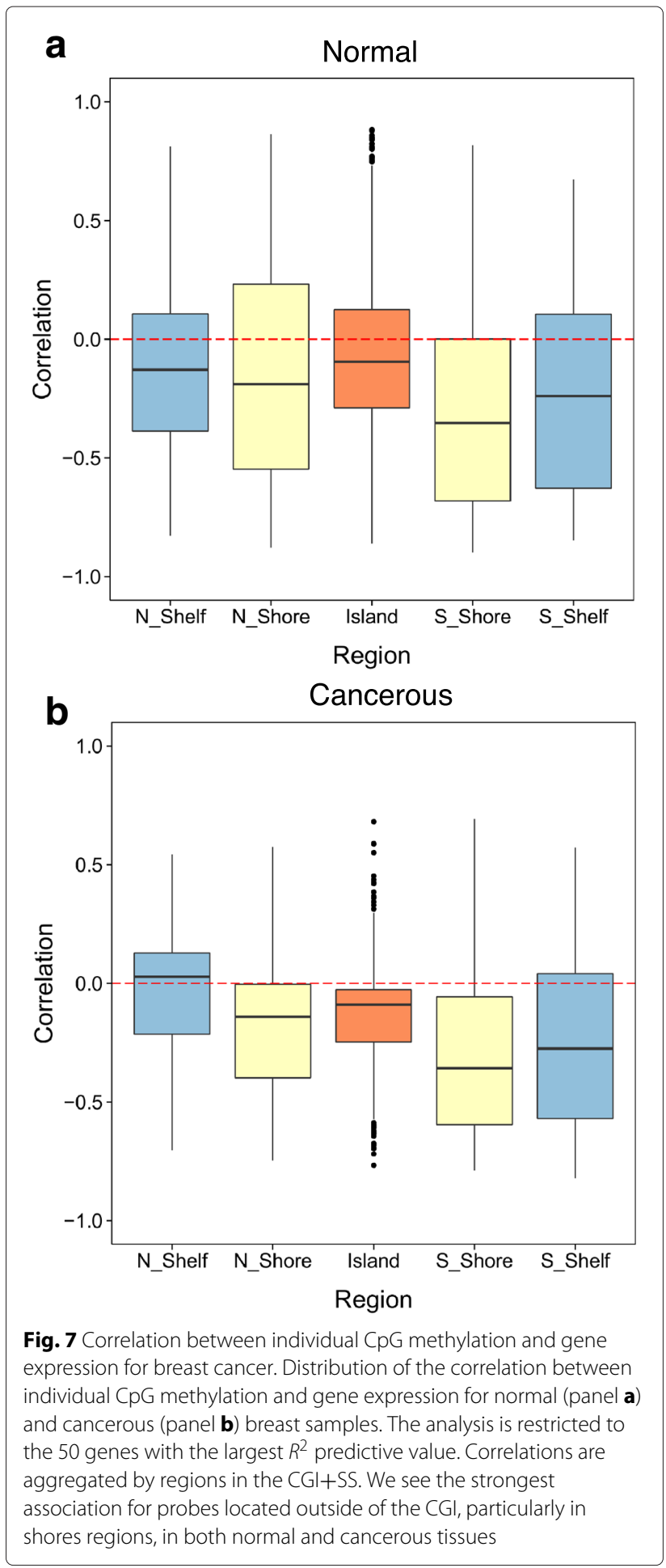

information, on the other hand. We observe that combining methylation and copy number information leads to significantly better results in predicting gene expression than taking each information separately (Fig. 9a, Additional files $16-17 \mathrm{a}, P_{\text {Breast }}<10^{-16}, P_{\text {Lung }}<10^{-9}$, 


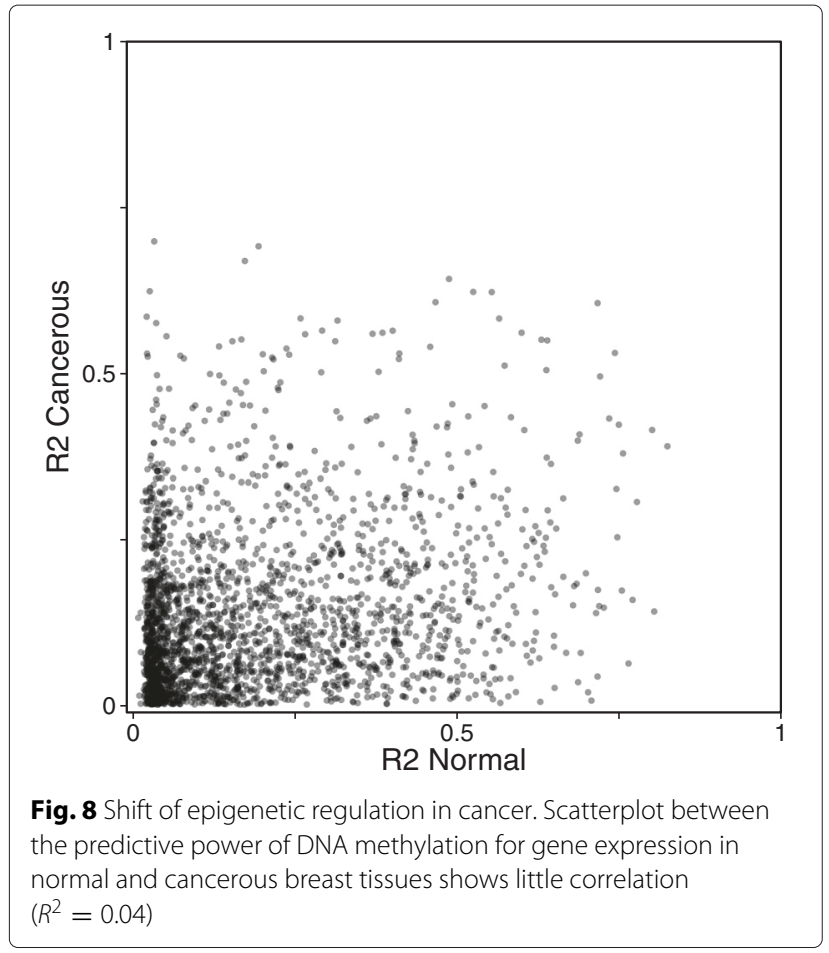

$\left.P_{\text {Colon }}<10^{-8}\right)$. Moreover, correlation analysis between predictive scores using DNA methylation only, on the one hand, and predictive scores using CNVs only, on the other hand, shows very little correlation $\left(R_{\text {Breast }}^{2}=7 \times 10^{-4}\right.$, $R_{\text {Lung }}^{2}=1 \times 10^{-4}, R_{\text {Colon }}^{2}=1 \times 10^{-3}$, Fig. 9b, Additional files 16-17b). This suggests that both methylation and DNA CNVs are important and non-redundant predictors of gene expression variation.

\section{Discussion}

DNA methylation is a well-described process in normal development and is critical in specific gene expression regulations such as $\mathrm{X}$-chromosome inactivation, genomic imprinting and tissue developpment [2-5]. Since aberrant hyper- and hypo-methylation have also been frequently observed in cancer, it has been often argued that activation of oncogenes or repression of tumor suppressor genes could be caused by these epigenetic variations [6].

In the present study, we assessed the existence of characteristic CGI+SS DNA methylation signatures in normal tissues and showed a weak association between the hyper-methylated signature and gene expression repression. A similar study in cancerous tissues showed the existence of a cancer-specific signature highly associated with repressed genes. However, the corresponding genes are already highly repressed in normal tissues, questioning the causal impact of methylation in gene expression regulation, as already observed $[18,19,21]$.
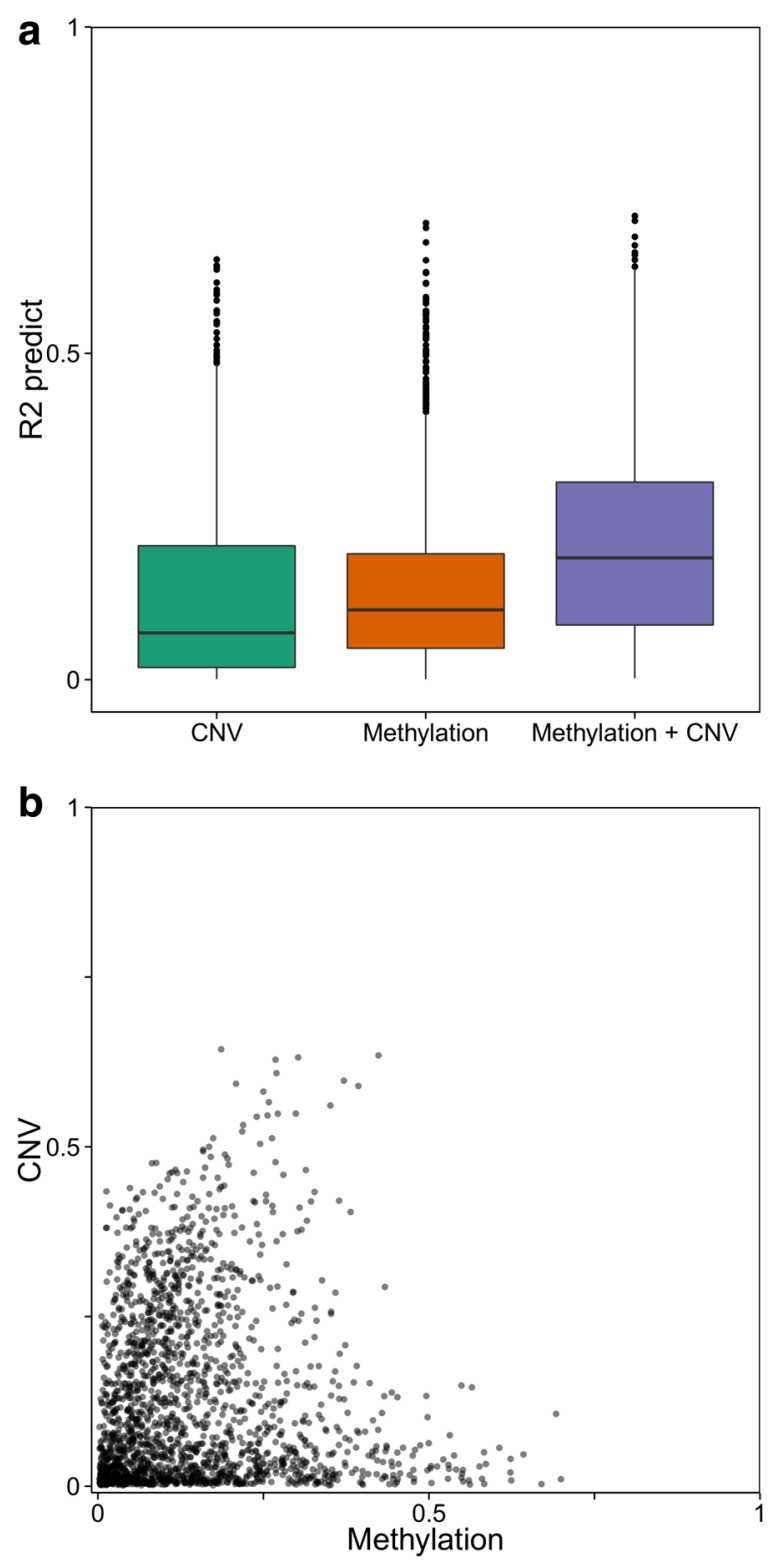

Fig. 9 Association between predictive power of methylation and CNVs. Panel a Predictive power distribution using either CNV data only with least squares, DNA methylation data only with lasso regression or both CNV and DNA methylation data with lasso regression. Combined methylation and CNV information yield significantly higher predictive power $\left(P<10^{-16}\right)$. Panel $\mathbf{b}$ Scatterplot of predictive power using DNA methylation only and copy number information only shows that both regulation mechanisms operate exclusively on genes $\left(R^{2}=6 \times 10^{-4}\right)$

Using regression methods we analyzed whether differences between CGI+SS methylation across samples independently of signatures - are predictive of gene expression variation. We showed that for certain genes, expression variations across samples can be well predicted from DNA methylation and that these genes are not associated with cancer-specific methylation patterns. We also showed that using the full CGI+SS methylation profiles 
in a multidimensional regression framework yields better predictive power than summarizing the methylation of a CpG island by one mean value, as done in previous studies [32]. Looking at probewise methylation correlation with gene expression for the top scoring genes, we observed that the impact of a CpG methylation on gene expression is largely dependent on its location in or near the island, and that CpGs located outside of CGIs have a bigger impact on gene expression variations than $\mathrm{CpG}$ located within the CGI, in accordance with [11, 33]. The impact of CGIs located outside of promoter regions, such as intragenic CGIs is still unclear as it does not seem to contribute significantly to global gene expression regulation. Yet, a few studies point at their potential role in modulating alternative promoters [34] or in long-range regulation [35].

Reproducing this methodology on different datasets allowed us to compare the variations of gene expression regulation by methylation in normal and cancerous tissues but also between different types of tissues. Our results suggest that genes targeted by methylation are not only very different between different normal tissues, but more importantly that they are very different between normal and cancerous samples of a given tissue suggesting a shift of epigenetic regulation between normal and cancerous tissues. Recently, hydroxymethylation of cytosines (hmC) has been shown to be significantly present in mammalians cells [36] and methylation data generated with Illumina arrays, as done here, are not able to distinguish methylation $(\mathrm{mC})$ from hmC [37]. However, hydroxymethylation is significantly less observed in cancer tissues [38, 39]. It is therefore likely that the epigenetic information measured here is indeed cytosine methylation.

In addition, the association between DNA methylation and other important regulation mechanisms widens our understanding of the role of methylation in the whole gene expression regulation process. While TFs are essential for controlling gene expression, we showed that their activation itself is significantly associated with DNA methylation markers, highlighting the critical role of methylation in the regulatory process. CNVs have been widely analyzed as a source of genetic variation that plays an important role in complex phenotypes such as cancer [31, 40]. While CNV contribution has been characterized on a genome-wide scale, the link with other regulation mechanisms, particularly DNA methylation, is still unclear $[41,42]$. We showed that the impact of both processes in gene expression regulation seems to be non-redundant. The relatively large dataset size gives us confidence in the statistical validity of the results, which are however limited to a fraction of the total genes because of uneven coverage. Methylome sequencing has already been performed and also supports the complexity of methylation patterns but is still limited to very small datasets [32]. Undoubtedly, larger methylome datasets available in the near future will further improve our understanding of the role of DNA methylation in gene expression regulation.

\section{Conclusions}

In summary, this study suggests that promoter methylation profiles can be summarized with a few characteristic profiles that we refer to as $\mathrm{CGI}+\mathrm{SS}$ methylation signatures. In cancer, we observe an epigenetic reprogramming that leads to the apparition of a cancer-specific CGI+SS methylation signa- ture. However, this epigenetic reprogramming is not associated changes in gene expression, suggesting that this mechanism does not contribute to cancer development via direct inhibition of gene expression through promoter hypermethylation. On the other hand, we observe that genes which demonstrate high correlation between methylation variations and gene expression variations differ from normal to cancer- ous tissues. This suggests that in cancer, the association between gene expression and promoter DNA methylation is modified.

\section{Materials and methods}

\section{Patients selection}

All data were retrieved from the TCGA data portal. We selected samples from breast, colon and lung adenocarcinomas because large matched datasets were available for methylation, gene expression and copy number profiles. The datasets are detailed in Table 1 and the different institutions that released the data are mentioned in the acknowledgement section.

\section{Methylation profiling}

Methylation profiles were retrieved from level 2 TCGA data. They were obtained with the Illumina HumanMethylation450K DNA Analysis BeadChip assay, which is based on genotyping of bisulfite-converted genomic DNA at individual CpG-sites to provide a quantitative measure of DNA methylation [43]. Following hybridization, the methylation value for a specific probe was calculated as the ratio $M /(M+U)$ where $M$ is the methylated signal intensity and $U$ is the unmethylated signal intensity. 485,577 CpG methylation levels, associated with 27,176 CGIs and 21,231 genes, were measured as such accross the genome.

Following [11], we considered not only the CGI methylation profile but also included in the analysis proximal regions in the near vicinity (up to $4 \mathrm{~kb}$ ), namely the CGI Shores and Shelves regions in a general CGI+SS methylation profile. As we were interested in the coordinated variations of methylation, we restricted the analysis to CGI+SS profiles containing at least 20 probes which reduced the analysis to $1827 \mathrm{CGI}+\mathrm{SS}$ associated with 2,374 genes from the original dataset. 


\section{Gene expression profiling}

Gene expression profiles were retrieved from level 3 TCGA data. They were obtained from the Illumina HiSeq RNASeq technology and processed following [44].

\section{CNV processing}

CNVs were retrieved from the level 3 TCGA data infered from Affymetrix SNP6.0 data files in GenePattern following [45]. For each gene, we then obtained the $\log$ ratio copy number score as the segmented log ratio score for the interval containing its transcription start site.

\section{Combined CpG island, shores and shelves pattern analysis}

CGI+SS patterns were compared using dynamic time warping (DTW) [46] as it is less sensitive to small variations than the Fréchet distance [47]. Dynamic time warping was originally applied as a speech signal similarity measure and has been applied with success in several other fields including computer vision [48], protein structure matching [49] and time series analysis [50].

A CGI+SS profile $i$ can be represented as a couple of vector $\left(X^{i}, Y^{i}\right)=\left(\left(x_{1}^{i}, y_{1}^{i}\right), \ldots,\left(x_{n}^{i}, y_{n}^{i}\right)\right)$ where $x_{k}^{i}$ represents the position of the $k^{\text {th }}$ CpG associated with the CGI+SS and $y_{k}^{i} \in[0 ; 1]$ represents the mean methylation level for this probe accross a given dataset. For two CGI+SS profiles with respectively $m$ and $n$ probes, we compute the distance between the two profiles as:

$$
\operatorname{DTW}\left(C G I_{1}, C G I_{2}\right)=\min _{w \in \text { Path }} \sum_{k=1}^{\text {length }(w)}\left|y_{w_{1}^{k}}^{1}-y_{w_{2}^{k}}^{2}\right|^{2},
$$

where a path $w$ of length $K$ is a pair of vectors $\left(w_{1}^{k}, w_{2}^{k}\right)_{k \in[1: K]}$ in $[1 ; m] \times[1 ; n]$ that verifies:

- $\left(w_{1}^{1}, w_{2}^{1}\right) \in\{1\} \times[1 ; n] \cup[1 ; m] \times\{1\}$ (partial initialization)

- $\forall i \in\{1 ; 2\}, w_{i}^{k+1}=w_{i}^{k}$ or $w_{i}^{k+1}=w_{i}^{k}+1$ (monotonicity and continuity)

- $\left(w_{1}^{K}, w_{2}^{K}\right) \in\{n\} \times[1 ; n] \cup[1 ; m] \times\{n\}$ (partial boundary condition)

The algorithm is applied for each pair of CGI+SS patterns to obtain a dissimilarity matrix. Ward hierarchical clustering is then performed on this dissimilarity matrix to assess the existence of characteristic patterns amongst the different datasets.

The number of significant clusters is assessed through bootstrapping $\left(n_{\text {repeats }}=100\right)$ on a random subset of CGI+SS of the initial dataset (ratio $=80 \%$ of the total number of CGI+SS) following Ben-Hur et al [51]. R code for analysis is available upon request.

\section{Survival analysis}

Overall survival was estimated using the Kaplan-Meier method [52] to compare the survival between the group of patients with a lower level of methylation in the hemimethylated CGI+SS compared to the group of patients with a higher level of methylation. A multivariate Cox proportional hazards regression model [53] was also fitted to estimate the additional value of this classification as a predictive factor for survival compared to other clinical parameters such as age, tumor size, lymph node status, receptor status and HER2/NEU status.

\section{Computing gene expression susceptibility to DNA methylation changes}

We apply ridge [54] and LASSO [55] multivariate regression methods to predict gene expression using the full CGI+SS methylation profiles as well as univariate least square regression when using only the averaged methylation from the whole CGI+SS profile. Following Acharjee et al. [56], we assess the predictive power of the methylation using the predictive goodness of fit $R^{2}$ which represents the squared Pearson correlation between observed and fitted values on an independent dataset. The estimation of the predictive power for each gene is obtained through 3-fold cross-validation averaged over 100 repeats. Parameters for both lasso and ridge regression methods were obtained by minimizing the mean squared error function using nested 3-fold cross-validation on the training dataset. The use of the predictive goodness of fit instead of the classic mean squared error as a score allows to compute a comparable score between different predictions. In particular, the mean squared error is highly affected by the absolute level of gene expression while the $R^{2}$ is invariant to scaling. It is also important to note that in this case the $R^{2}$ computed for least square regression is a prediction $R^{2}$ and not just a goodness-of-fit of the given dataset and therefore provides confidence on the generalization of the score on independent datasets. $\mathrm{R}$ code for analysis is available upon request.

\section{Additional files}

Additional file 1: Hierarchical clustering of average $\mathrm{CGI}+\mathrm{SS}$ patterns for lung tissues. (PDF $136 \mathrm{~kb}$ )

Additional file 2: Hierarchical clustering of average $\mathrm{CGI}+\mathrm{SS}$ patterns for colon tissues. (PDF $135 \mathrm{~kb}$ )

Additional file 3: Characteristic profiles of CGI+SS clusters in lung tissues. (PDF $1249 \mathrm{~kb}$ )

Additional file 4: Characteristic profiles of CGI+SS clusters in colon tissues. (PDF $1311 \mathrm{~kb}$ )

Additional file 5: Example of CGls with different methylation patterns between normal and tumor samples (full dark blue line=cluster 1 in normal samples, dashed green line=cluster 3up in tumor samples). The black vertical bars represent the position of the $\mathrm{CpG}$ island. (PDF $922 \mathrm{~kb}$ )

Additional file 6: Gene ontology analysis for the genes associated with cancer-specific cluster 3. (PDF $72 \mathrm{~kb}$ )

Additional file 7: Gene expression patterns for each CGI+SS clusters in lung tissues. (PDF $286 \mathrm{~kb}$ ) 
Additional file 8: Gene expression patterns for each CGI+SS clusters in colon tissues. (PDF $5.18 \mathrm{~kb}$ )

Additional file 9: Clinical impact of cluster "3up". Multivariate Cox regression analysis including the level of methylation in the cancer-specific cluster "3up" in addition to all clinical variables available for breast cancer. (CSV $4091 \mathrm{~kb}$ )

Additional file 10: Hierarchical clustering of breast cancer patients based on the average methylation level of $\mathrm{CGI}+\mathrm{SS}$ associated with cluster 3down. (PDF $379 \mathrm{~kb}$ )

Additional file 11: Impact of DNA methylation on gene expression prediction. (PDF $156 \mathrm{~kb}$ )

Additional file 12: Top genes regulated by methylation for breast normal tissues, lung normal and cancerous tissues and colon cancerous tissues. (CSV $3.48 \mathrm{~kb}$ )

Additional file 13: Methylation association with gene expression by regions. Panel A. Colon cancerous samples. Panel B. Lung normal samples. Panel C. Lung cancerous samples. (PDF $252 \mathrm{~kb}$ ) Additional file 14: Tissue-specificity of methylation for gene expression regulation in normal and cancerous tissues. Panel A. normal breast and lung samples. Panel B. cancerous breast and colon samples. Panel C. cancerous colon and lung samples. Panel D. cancerous lung and breast samples. (PDF $714 \mathrm{~kb}$ )

Additional file 15: Shift of epigenetic regulation between normal and cancerous lung tissues. (PDF $135 \mathrm{~kb}$ )

Additional file 16: Specific increase of predictive power for aberrant CNV by including copy number profiles in lung tissues. (PDF $415 \mathrm{~kb}$ )

Additional file 17: Specific increase of predictive power for aberrant CNV by including copy number profiles in colon tissues. (PDF $367 \mathrm{~kb}$ )

\section{Abbreviations}

CGI: CpG Island; CGI+SS: Combined CpG Island, CGI shores and shelves; CNV: Copy number variation; GRM: Gene regulated by methylation; TF:

Transcription factor; DTW: Dynamic time warping

\section{Competing interests}

The authors declare that they have no competing interests.

\section{Authors' contributions}

MM and VB participated in the statistical analyses and the writing of the manuscript. JPV and FR conceived the study and participated in its design and coordination. All authors read and approved the final manuscript.

\section{Acknowledgements}

This study was financially supported by "La Ligue Nationale Contre le Cancer" (to M.M), the European Research Council (SMAC-ERC-280032 to J-P.V).

The authors would like to acknowledge the Cancer Genome Atlas, the UCSF ${ }^{1 a}$ the Walter Reed ${ }^{1 a}$, the Christiana Healthcare ${ }^{1 a, 2 a, 3 a, 3 b}$, Indivumed ${ }^{1 a, 2 a, 3 a, 2 b}$, Cureline ${ }^{1 a, 3 a}$, the Memorial Sloan Kettering Cancer Center ${ }^{1 a}$, UNC $^{2 a, 3 a, 3 b}$, Mayo $^{1 a}$, Duke ${ }^{1 a}$, the University of Pittsburgh ${ }^{1 a}, 1 b$, ILSBio $^{1 a}$, Greater Poland Cancer Center ${ }^{1 a}$, Roswell Park ${ }^{1 a, 1 b, 3 a, 3 b}$, Washington University $3 a$, Johns Hopkins $^{3 a, 3 b}$, the International Genomics Consortium ${ }^{3 a, 3 b}$, Fox Chase $^{3 a}$, St Joseph's Medical Center ${ }^{3 a}$ for the distribution of patients data (as specified below).

Patients data legend:

${ }^{1}$ breast tissue

${ }^{2}$ colon tissue

${ }^{3}$ lung tissue

${ }^{a}$ cancerous

${ }^{b}$ healthy

\section{Author details}

${ }^{1}$ CBIO-Centre for Computational Biology, Mines Paristech, PSL-Research University, 35 Rue Saint-Honore, F-77300 Fontainebleau, France. ${ }^{2}$ Department of Bioinformatics, Biostatistics and System Biology, Institut Curie, 11-13 Rue Pierre et Marie Curie, F-75248 Paris, France. ${ }^{3}$ U900, INSERM, $11-13$ Rue Pierre et Marie Curie, F-75248 Paris, France. ${ }^{4}$ UMR932, Immunity and Cancer Team,
Institut Curie, 26 Rue d'Ulm, 75006 Paris, France. ${ }^{5}$ Department of Translational Research, Residual Tumor and Response to Treatment Team, Institut Curie, 26 Rue d'Ulm, 75006 Paris, France. ${ }^{6}$ Department of Surgery, Institut Curie, 26 Rue d'Ulm, 75006 Paris, France.

Received: 11 May 2015 Accepted: 6 October 2015

Published online: 28 October 2015

\section{References}

1. Newell-Price J, Clark AJL, King P. DNA Methylation and Silencing of Gene Expression. Trends Endocrinol Metab. 2000;11(4):142-8

2. Laurent $L$, Wong E, Li G, Huynh T, Tsirigos A, Ong CT, et al. Dynamic changes in the human methylome during differentiation. Genome Res. 2010;20(3):320-1.

3. Smith ZD, Meissner A. DNA methylation: roles in mammalian development. Nat Rev Genet. 2013;14(3):204-0.

4. Pollex T, Heard E. Recent advances in X-chromosome inactivation research. Curr Opin Cell Biol. 2012;24(6):825-32.

5. Li E, Beard C, Jaenisch R. Role for DNA methylation in genomic imprinting. Nature. 1993;366:362-5.

6. Esteller M. CpG island hypermethylation and tumor suppressor genes: a booming present, a brighter future. Oncogene. 2002;21 (35):5427-40.

7. Ehrlich M. DNA methylation in cancer : too much, but also too little. Oncogene. 2002;21:5400-413.

8. Laird PW, Jaenisch R. DNA methylation and cancer. Hum Mol Genet. 1994;3:1487-95

9. Das PM, Singal R. DNA methylation and cancer. J Clin Oncol. 2004;22(22): 4632-2.

10. Kulis M, Esteller M. DNA methylation and cancer. Adv Genet. 2010;70(10): $27-56$.

11. Irizarry RA, Ladd-Acosta C, Wen B, Wu Z, Montano C, Onyango P, et al. Genome-wide methylation analysis of human colon cancer reveals similar hypo- and hypermethylation at conserved tissue-specific CpG island shores. Nat Genet. 2009;41(2):178-86.

12. Qu Y, Lennartsson A, Gaidzik VI, Deneberg S, Karimi M, et al. Differential methylation in CN-AML preferentially targets non-CGI regions and is dictated by DNMT3A mutational status and associated with predominant hypomethylation of HOX genes. Epigenetics. 2014;9(8):1108-19.

13. Meissner A, Mikkelsen TS, Gu H, Wernig M, Sivachenko A, Zhang X, et al. Genome-scale DNA methylation maps of pluripotent and differentiated cells. Nature. 2008;454(7205):766-70.

14. Lister R, Pelizzola M, Dowen RH, Hawkins RD, Hon G, Tonti-Filippini J, et al. Human DNA methylomes at base resolution show widespread epigenomic differences. Nature. 2009;462(7271):315-22.

15. Zhang Y, Liu H, LV J, Xiao X, Zhu J, Liu X, et al. QDMR: a quantitative method for identification of differentially methylated regions by entropy. Nucleic Acids Res. 2011;39(9):58.

16. Hansen $\mathrm{KD}$, Langmead $\mathrm{B}$, Irizarry RA. BSmooth: from whole genome bisulfite sequencing reads to differentially methylated regions. Genome Biol. 2012;13(10):83.

17. Varley KE, Gertz J, Bowling KM, Parker SL, Reddy TE, Pauli-Behn F, et al. Dynamic DNA methylation across diverse human cell lines and tissues. Genome Res. 2013;23(3):555-67.

18. Keshet I, Schlesinger $Y$, Farkash S, Rand E, Hecht M, Segal E, et al. Evidence for an instructive mechanism of de novo methylation in cancer cells. Nat Genet. 2006;38(2):149-53.

19. Sproul D, Nestor C, Culley J, Dickson JH, Dixon JM, Harrison DJ, et al. Transcriptionally repressed genes become aberrantly methylated and distinguish tumors of different lineages in breast cancer. Proc Nat Acad Sci USA. 2011;108(11):4364-9.

20. Sproul D, Kitchen RR, Nestor CE, Dixon JM, Sims AH, Harrison DJ, et al. Tissue of origin determines cancer-associated CpG island promoter hypermethylation patterns. Genome Biol. 2012;13(10):R84. doi:10.1186/gb-2012-13-10-r84.

21. Sproul D, Meehan RR. Genomic insights into cancer-associated aberrant CpG island hypermethylation. Brief Funct Genomics. 2013;12(3):174-90.

22. Timp W, Feinberg AP. Cancer as a dysregulated epigenome allowing cellular growth advantage at the expense of the host. Epigenet Genet. 2013;13(July)497-510. 
23. Timp W, Bravo HC, McDonald OG, Goggins M, Umbricht C, Zeiger M. et al. Large hypomethylated blocks as a universal defining epigenetic alteration in human solid tumors. Genome Med. 2014;6(61):61.

24. Reddington JP, Sproul D, Meehan RR. DNA methylation reprogramming in cancer: does it act by re-configuring the binding landscape of Polycomb repressive complexes? Bioessays. 2014;36(2):134-40.

25. Toyota M, Ahuja N, Ohe-Toyota M, Herman JG, Baylin SB, Issa J-PJ. CpG island methylator phenotype in colorectal cancer. Proc Natl Acad Sci. 1999;96(July):8681-6.

26. Yu G, Wang LG, Han Y, He QY. clusterProfiler: an R package for comparing biological themes among gene clusters. Omics: J Integrative Biol. 2012;16(5):284-7.

27. Hughes LAE, Melotte V, de Schrijver J, de Maat M, Smit VTHBM, Bovée JVMG, et al. The CpG island methylator phenotype: what's in a name? Cancer Res. 2013;73(19):5858-68.

28. Struhl K. Fundamentally Different Logic of Gene Regulation in Eukaryotes and Prokaryotes. Cell. 1999;98:1-4.

29. Zhang HM, Chen H, Liu W, Liu H, Gong J, Wang H, et al. AnimalTFDB: a comprehensive animal transcription factor database. Nucleic Acids Res. 2012:40(Database issue):144-9.

30. Vaquerizas JM, Kummerfeld SK, Teichmann Sa, Luscombe NM. A census of human transcription factors: function, expression and evolution. Nat Rev Genet. 2009;10(4):252-63.

31. Stranger BE, Forrest MS, Dunning M, Ingle CE, Beazley $C$, Thorne $N$, et al. Relative impact of nucleotide and copy number variation on gene expression phenotypes. Sci (New York, N.Y.) 2007;315(5813):848-53.

32. Vanderkraats ND, Hiken JF, Decker KF, Edwards JR. Discovering high-resolution patterns of differential DNA methylation that correlate with gene expression changes. Nucleic Acids Res. 2013:41(14):6816-27.

33. van Vlodrop IJH, Niessen HEC, Derks S, Baldewijns MMLL, van Criekinge W, Herman JG, et al. Analysis of promoter CpG island hypermethylation in cancer: location, location, location!. Clin Cancer Res. 2011;17(13):4225-31.

34. Maunakea AK, Chepelev I, Cui K, Zhao K. Intragenic DNA methylation modulates alternative splicing by recruiting MeCP2 to promote exon recognition. Cell Res. 2013;23(11):1256-69.

35. Kulis M, Queirós AC, Beekman R, Martín-Subero Jl. Intragenic DNA methylation in transcriptional regulation, normal differentiation and cancer. Biochimica et Biophysica Acta. 2013;1829(11):1161-74

36. Kriaucionis $\mathrm{S}$, Heintz $\mathrm{N}$. The nuclear DNA base 5-hydroxymethylcytosine is present in Purkinje neurons and the brain. Science. 2009;324:929-30.

37. Nestor C, Ruzov A, Meehan R, Dunican D. Enzymatic approaches and bisulfite sequencing cannot distinguish between 5-methylcytosine and 5-hydroxymethylcytosine in DNA. Biotechniques. 2010;48:317-9.

38. Haffner M, Chaux A, Meeker A, Esopi D, Gerber J, Pellakuru L, et al. Global 5-hydroxymethylcytosine content is significantly reduced in tissue stem/progenitor cell compartments and in human cancers. Oncotarget. 2011;2:627-37.

39. Jin $S$, Jiang $Y$, Qiu R, Rauch T, Wang Y, Schackert G, et al. 5-hydroxymethylcytosine is strongly depleted in human cancers, but its levels do not correlate with IDH1 mutations. Cancer Res. 2011;71: 7360-365.

40. Henrichsen CN, Chaignat E, Reymond A. Copy number variants, diseases and gene expression. Hum Mol Genet. 2009;18(R1):1-8.

41. Houseman EA, Christensen BC, Karagas MR, Wrensch MR, Nelson HH Wiemels $\mathrm{JL}$, et al. Copy number variation has little impact on bead-array-based measures of DNA methylation. Bioinformatics (Oxford, England). 2009;25(16):1999-2005.

42. Lauss M, Aine M, Sjödahl G, Veerla S, Patschan O, Gudjonsson S, et al. DNA methylation analyses of urothelial carcinoma reveal distinct epigenetic subtypes and an association between gene copy number and methylation status. Epigenetics. 2012;7(8):858-67.

43. Bibikova M, Barnes B, Tsan C, Ho V, Klotzle B, Le JM, et al. High density DNA methylation array with single $\mathrm{CpG}$ site resolution. Genomics. 2011;98(4):288-95.

44. Mortazavi A, Williams BA, Mccue K, Schaeffer L, Wold B. Mapping and quantifying mammalian transcriptomes by RNA-Seq. Nat Methods. 2008;5(7):1-8

45. Reich M, Liefeld T, Gould J, Lerner J, Tamayo P, Mesirov JP. GenePattern 2.0. Nat Genet. 2006;38(5):500-1.

46. Rabiner L, Juang BH. Fundamentals of Speech Recognition. Upper Saddle River, NJ, USA: Prentice-Hall, Inc.; 1993.
47. Efrat A, Fan Q, Venkatasubramanian S. Curve Matching, Time Warping and Light Fields: New Algorithms for Computing Similarity between Curves. J Math Imaging Vis. 2006;27(3):203-16.

48. Serra B, Berthod M. Subpixel contour matching using continuous dynamic programming. In: Computer Vision and Pattern Recognition 1994. Proceedings CVPR '94, 1994 IEEE Computer Society Conference; 1994. p. 202-207.

49. Wu TD, Schmidler SC, Hastie T, Brutlag DL. Regression analysis of multiple protein structures. J Comput Biol. 1998;5(3):585-95.

50. Keogh EJ, Pazzani MJ. Scaling up Dynamic Time Warping to Massive Datasets. Proc 3rd Eur Conf Principles Prac Knowl Discov Databases (KDD). 1999;1704:1-11.

51. Ben-Hur A, Elisseeff A, Guyon I. A stability based method for discovering structure in clustered data. Pac Symp Biocomput. 2002;17:6-17.

52. Kaplan EL, Meier D. Nonparametric estimation from incomplete observation. J Am Statist. 1958;58:457-81.

53. Cox DR, Oakes D. Analysis of Survival Data. London: Chapman and Hall; 1984.

54. Hoerl AE, Kennard RW, Kennard W. Ridge Regression : Applications to Nonorthogonal Problems. Technometrics. 1970;12(1):69-82.

55. Tibshirani R. Regression Shrinkage and Selection via the Lasso. J R Stat Soc. 1996;58(1):267-88.

56. Acharjee A, Finkers R, Visser RGF, Maliepaard C. Comparison of Regularized Regression Methods for Omics Data. Metabolomics. 2013;3:126.

\section{Submit your next manuscript to BioMed Central and take full advantage of:}

- Convenient online submission

- Thorough peer review

- No space constraints or color figure charges

- Immediate publication on acceptance

- Inclusion in PubMed, CAS, Scopus and Google Scholar

- Research which is freely available for redistribution

Submit your manuscript at

www.biomedcentral.com/submit
C BiolMed Central 